\title{
Emotional Branding Dalam Strategi Pemasaran Kolaborasi : Studi Kasus Desain Kemasan Mizzu "Khong Guan Face Palette"
}

\author{
Monica Revias Purwa Kusuma', Aji Susanto Anom Purnomo² \\ ${ }^{1}$ Desain Komunikasi Visual, Fakultas Rekayasa Industri dan Desain, Institut Teknologi Telkom Purwokerto \\ Jl.D.I Panjaitan No.128 Purwokerto, Indonesia
}

${ }^{2}$ Fotografi, Fakultas Seni Media Rekam, Institut Seni Indonesia Yogyakarta

Jl. Parangtritis Km. 6,5 Sewon, Bantul, Yogyakarta, Indonesia

${ }^{1}$ revias@ittelkom-pwt.ac.id

Di era internet marketing saat ini, pengambilan keputusan pembelian sebuah produk tidak hanya bergantung pada fungsinya saja. Faktor emosional dan nilai artistik juga memiliki peran didalam proses tersebut. Hal ini membutuhkan strategi pemasaran yang kreatif dan inovatif agar sebuah produk sukses dalam pemasarannya. Penelitian ini bertujuan memaparkan fenomena strategi pemasaran yang dilakukan oleh Mizzu Cosmetics sebagai alternatif dalam merencanakan sebuah strategi pemasaran. Strategi pemasaran tersebut adalah strategi pemasaran kolaborasi yang dilakukan oleh Mizzu Cosmetics bersama biskuit Khong Guan dalam produk "Khong Guan Face Palette". Penelitian ini menggunakan metode penelitian deskriptif kualitatif berlandaskan fenomenologis dengan teori utama desain kemasan dan ditunjang oleh teori emotional branding serta teori strategi pemasaran. Dari hasil penelitian didapat strategi pemasaran kolaborasi yang kreatif dan inovatif memanfaatkan aspek emotional branding dari sebuah produk yang ikonik. Biskuit Khong Guan yang sudah lebih dulu lekat di benak konsumen dengan parodi dan meme hilangnya sosok ayah memberikan nilai tambahan pada produk Mizzu Cosmetics dalam desain kemasannya serta rangkaian kampanye yang dilakukan

Kata kunci : desain kemasan, mizzu kosmetik, emotional branding

\section{Emotional Branding In Collaboration Marketing Strategy: Case Study Of Mizzu Packaging Design "Khong Guan Face Palette"}

In the era of internet marketing, the decision making to buy a product does not depend only on the product alone. The emotional and artistic value also have an important role in the process. It requires creative and innovative marketing strategies for the product to reach the market better. This reasearch aims to describe the marketing strategies by mizzu cosmetics as an alternative to plan a marketing strategies in the internet marketing era. This strategies is conducted by collaboration of mizzu cosmetics and biscuit khong guan in the "Khong Guan Face Palette" product. This study using a method of descriptive qualitative research based on a fenomenology with the grand theory of packaging design and supported by the theory of emotional branding and marketing strategies. Presented from the result of the research is the marketing strategy of creative collaboration and innovation use of the emotional branding aspects of a product that already iconic. The Khong Guan product would already been drawn in the minds of consumers with a parody and the meme loss of a father figure that give an added value to mizzu cosmetics product in the package design as well as a series of campaign.

Keywords : packaging design, mizzu cosmetic, emotional branding

Proses Review : 18 - 31 Agustus 2020, Dinyatakan Lolos: 7 September 2020 


\section{PENDAHULUAN}

Perkembangan strategi pemasaran sebuah produk saat ini tidak hanya menitikberatkan pada kebutuhan konsumen terhadap fungsi sebuah produk. Sebuah produk adalah segala sesuatu yang ditawarkan oleh produsen terhadap konsumen untuk memenuhi kebutuhan atau keinginannya. Pasar yang selalu berkembang membutuhkan strategi pemasaran yang terkini dan adaptif terhadap selera konsumen. Salah satu strategi pemasaran yang inovatif saat ini adalah melakukan kolaborasi antar produk lintas fungsi. Dalam era New Wave, kolaborasi menjadi cara terbaru untuk menambah nilai pada suatu produk karena bisa mendapat perhatian konsumen dan bertujuan mendapatkan rekomendasi dari mulut ke mulut (Kotler, 2017:227). Desain kemasan merupakan salah satu alat komunikasi sebuah produk kepada target marketnya. Kemasan yang semula berfungsi untuk melindungi suatu produk sudah mengalami pergeseran fungsi menjadi alat pemasar suatu produk dengan mengkomunikasikan fungsi produk secara unik (Klimchuk, 2007:33). Pada umumnya, bentuk dan visualisasi desain kemasan mengacu pada sebuah merek produk yang dipasarkan, akan tetapi ada fenomena unik yang muncul di era kolaborasi yaitu menggunakan visualisasi yang sama dengan merek lain yang sudah ikonik dan lebih dikenal masyarakat.

Fenomena tersebut berkembang luas diberbagai macam jenis produk. Beberapa contohnya yaitu lipstik Dear Me Beauty x Permen Yuppi, Indomie x Chitato, Etude House x Kitkat, Tony Moly x Samyang. Kolaborasi antar produk yang akan dijadikan studi kasus pada penelitian ini yaitu Mizzu Cosmetics x Khong Guan.

Mizzu Cosmetics adalah merek kosmetik lokal asal Indonesia yang tergolong berusia muda. Berdiri sejak 2012, hingga saat ini Mizzu tumbuh menjadi salah satu merek kosmetik yang memiliki keunikan dalam hal lini produk ataupun strategi pemasaran yang dilakukan (https://mizzucosmetics.com/about/). Salah satu strategi pemasaran yang inovatif dari Mizzu Cosmetics adalah berkolaborasi dengan beberapa merek dan salah satunya adalah Khong Guan dalam keluaran lini produk "Khong Guan Face Palette". Yang menonjol dari produk kolaborasi ini adalah persamaan visualisasi desain kemasan face pallete dengan desain kemasan kaleng Khong Guan yang menggunakan ilustrasi seorang ibu yang sedang makan bersama dua orang anaknya tanpa adanya figur seorang ayah. Ilustrasi dalam kaleng Khong Guan sendiri beberapa tahun belakangan menjadi sorotan para netizen karena banyak yang membuat parodi atau meme dimana keberadaan ayah dari keluarga tersebut.

Di era New Wave saat ini, masyarakat menilai sebuah produk lebih dari sekedar fungsi, yakni karena adanya hubungan emosi dengan suatu produk. Dengan memanfaatkan sisi emosional dari satu produk, produk yang lain

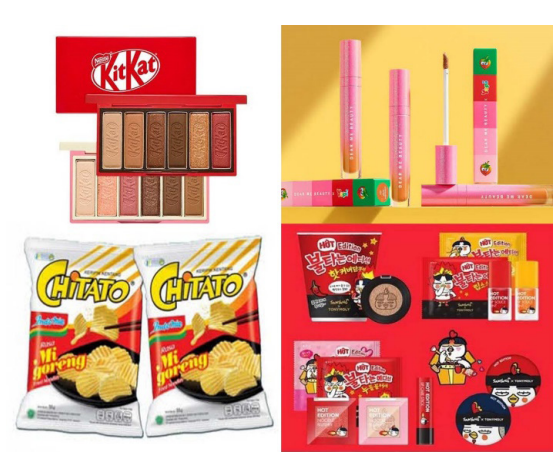

Gambar 1. Contoh Kolaborasi Antar Brand (Sumber: www.google.com)
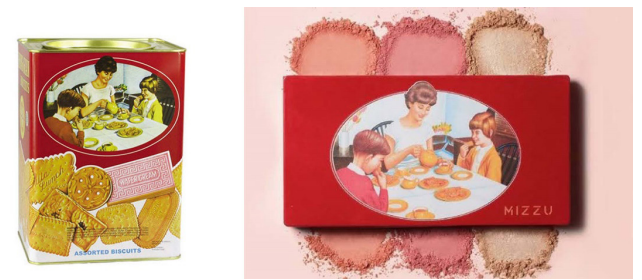

Gambar 2. Desain Kemasan Khong Guan (kiri) dan Mizzu Face Pallete x Khong Guan (kanan)

(Sumber: www.google.com)

bisa mendapatkan keuntungan dalam hal pemasarannya. Faktor emosi ikut berkontribusi dalam pengambilan keputusan yang dilakukan oleh konsumen terhadap suatu produk. Hal ini cukup berbeda dengan pemikiran kuno yang memandang aspek kognitif lebih berperan dibandingkan aspek emosi dalam pengambilan keputusan. Pengambilan keputusan terdiri tidak hanya melibatkan peran kognitif saja namun merupakan gabungan antara emosi dan kognitif (Norman, 2004:12). Berdasarkan penelitian pasar (market research) juga menunjukkan sangat sedikitnya konsumen yang membuat keputusan murni berdasarkan fungsi dari suatu produk (Roberts,2004:21). Strategi pemasaran yang memanfaatkan emotional branding dengan adanya kolaborasi Mizzu Cosmetics x Khong Guan ini merupakan hal yang inovatif dan penting untuk diteliti sebagai pilihan produsen dalam memenangkan persaingan pasar. Menurut Chandra (Chandra, 2002:93), strategi pemasaran adalah penjabaran rencana tentang ekspektasi perusahaan akan dampak beragamnya aktivitas atau program pemasaran terhadap permintaan produk atau lini produknya di pasar sasaran tertentu. Program pemasaran meliputi tindakan-tindakan pemasaran yang dapat mempengaruhi permintaan terhadap produk, diantaranya dalam hal mengubah harga, memodifikasi kampanye iklan, merancang promosi khusus, menentukan pilihan saluran distribusi, dan sebagainya.

Berpijak dari uraian latar belakang di atas memunculkan permasalahan yaitu bagaimana emotional branding bekerja dalam strategi pemasaran kolaboratif desain kemasan Mizzu "Khong Guan Face Palette"? Tujuan dari penelitian ini akan mendeskripsikan bagaimana emotional branding bekerja di dalam strategi pemasaran kolaboratif desain kemasan Mizzu "Khong Guan Face Palette. Penelitian ini 

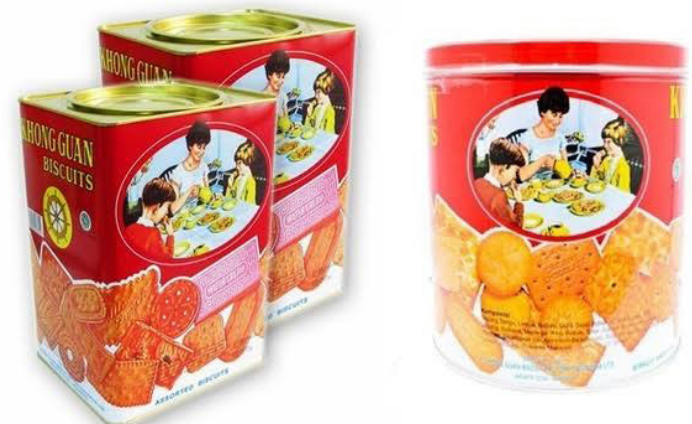

Gambar 3. Desain Kemasan Khong Guan ukuran kaleng besar dan kecil (Sumber: www.google.com)
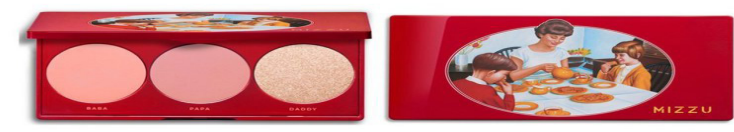

P

Gambar 4. Desain Kemasan Khong Guan ukuran kaleng besar dan kecil (Sumber: www.google.com)

dilakukan untuk memaparkan fakta-fakta terhadap fenomena strategi pemasaran kolaborasi yang dilakukan oleh objek penelitian yaitu produk "Khong Guan Face Palette" dari Mizzu Cosmetics.

Penelitian yang dihasilkan diharapkan memiliki kontribusi yang baik dan bisa digunakan sebagai rujukan yang berguna di ranah Desain Komunikasi Visual maupun di bidang pemasaran. Dengan mengetahui bagaimana emotional branding bekerja dengan menerapkan strategi pemasaran kolaboratif, diharapkan dapat menjadikan alternatif maupun pandangan bagi para pelaku desain agar bisa membranding sebuah produk agar lebih unik dan menarik.

\section{METODE PENELITIAN}

Metode penelitian yang di gunakan dalam penelitian ini adalah penelitian deskriptif kualitatif. Metode penelitian ini bertujuan untuk mendeskripsikan perilaku orang, peristiwa lapangan, serta kegiatan-kegiatan tertentu secara terperinci dan mendalam. Adapun yang dimaksud dengan penelitian deskriptif yaitu suatu penelitian untuk menggambarkan variabel yang berkenaan dengan masalah yang diteliti tanpa mempersoalkan hubungan antar variabel. Pendekatan penelitian yang digunakan dalam penelitian ini adalah metode penelitian deskriptif kualitatif yang berlandaskan fenomenologis. Fenomenologis yang dimaksud adalah fenomena-fenomena yang terjadi atau realita yang ada di lapangan penelitian. (Faisal, 1992: 18)

Sampel Penelitian yaitu produk Mizzu "Khong Guan Face Palette" yang di launching pada November 2019. Sampel penelitian tersebut diambil dari populasi penelitian produk-produk dari Mizzu Cosmetics. Metode peng- umpulan data yang digunakan yaitu observasi dan dokumentasi. Sumber data diperoleh dari pengkajian literatur baik dari buku ataupun media daring. Pengkajian arsip berupa dokumentasi diambil dari observasi langsung dan atau tidak langsung melalui media sosial dari Mizzu Cosmetics. Setelah semua sampel terkumpul maka dilakukan penelitian menggunakan pendekatan teori desain kemasan dan ditunjang dengan teori emotional branding serta teori strategi pemasaran.

\section{ANALISIS DAN INTEPRETASI DATA}

Daya tarik sebuah kemasan terletak pada elemen desainnya yang dirasa menarik. Empat penarik perhatian utama dalam desain kemasan yaitu warna, struktur fisik, simbol/ angka, dan tipografi (Klimchuk, 2007:82). Area utama yang dikhususkan untuk menempatkan identitas merek disebut Primary Display Panel (PDP), dan biasanya berada di depan desain kemasan. Area tersebut merupakan yang terpenting karena menjadi aspek visual komunikasi pemasaran dan strategi merek.

Kemasan Khong Guan terbuat dari kaleng yang di dominasi warna merah dengan adanya ilustrasi pada area PDP. Kaleng sendiri merupakan salah satu bahan kemasan yang terbuat dari logam yang biasanya terdiri dari bahan baja ataupun alumunium (Julianti, 2014:137-138). Kaleng Khong Guan sendiri menurut jenisnya yaitu terbuat dari bahan baja yang di coated dengan cat dengan gambar/ilustrasi di bagian luarnya. Ilustrasi tersebut menarik karena dibuat dengan teknik gambar manual yang berupa lukisan, baru di cetak ke kaleng tersebut. Lukisan tersebut merupakan karya dari Bernardus Prasodjo, yang merupakan pelukis kemasan yang tenar di tahun 1970an. Dalam ilustrasi tersebut digambarkan ada seorang ibu yang sedang makan bersama anak perempuan dan anak laki-lakinya. Ibu tersebut sedang menyeduh teh dan di depannya terhidang beberapa jenis biskuit. Di bawah ilustrasi sebuah keluarga tersebut terdapat beberapa ilustrasi bermacam-macam biskuit yang digambarkan memutar ke seluruh badan bawah kemasan. Ilustrasi biskuit tersebut merupakan gambaran biskuit apa saja yang didapatkan jika membeli biskuit Khong Guan. Tipografi pada desain kemasan adalah medium utama yang dapat mengkomunikasikan nama, fungsi, dan fakta produk bagi konsumen luas. Semua itu mempengaruhi dan menjadi elemen paling penting dari ekspresi visual produk (Klimchuk, 2007:87) Tipografi pada desain kemasan yang paling menonjol adalah tulisan dari merek produk tersebut yaitu KHONG GUAN BISCUITS yang menggunakan tipe huruf serif yang mengesankan ketegasan merek tersebut. Pada badan kemasan hanya ada keterangan-keterangan lain seperti komposisi, jenis produk, berat produk, alamat produsen, dan informasi lainnya yang tidak terlalu dominan terlihat.

Dalam desain kemasan produk Mizzu "Khong Guan Face Palette" ilustrasi dan warna yang digunakan sama persis 


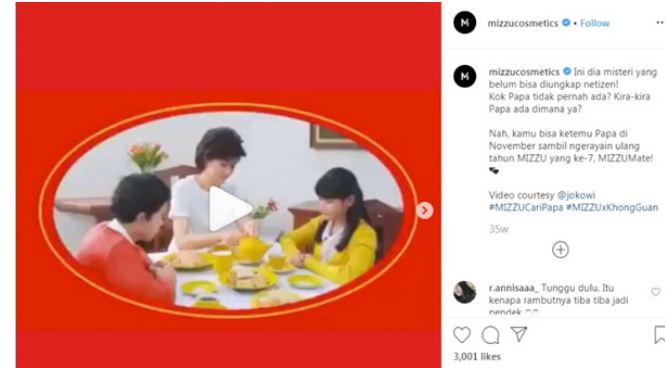

Gambar 5. Kampanye "\#MIZZUCariPapa" dari Mizzu Cosmetics

(Sumber: https://www.instagram.com/p/BxNHxlqlIRS/)

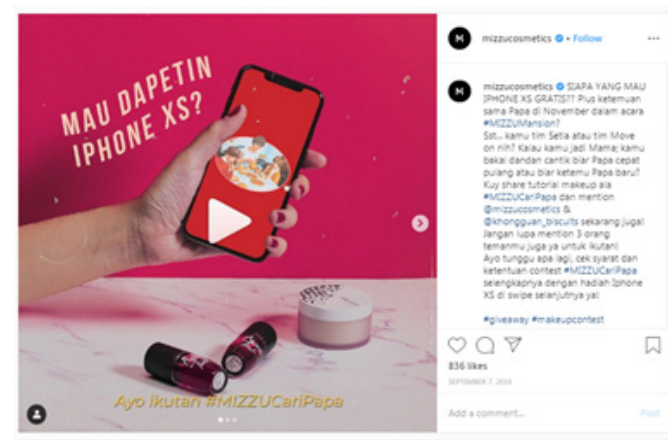

Gambar 6. Giveaway "Iphone XS" Dari Mizzu Cosmetics (Sumber: https://www.instagram.com/p/B2GsAawlhO2/)

dengan yang ada pada kemasan produk Khong Guan Biscuits. Perbedaan dalam visualisasi kedua kemasan tersebut hanya pada kemasan Mizzu Cosmetics tidak menuliskan merek Khong Guan pada kemasan produknya. Dalam kemasan produk Mizzu Cosmetics yang disematkan pada bagian PDP hanyalah merek MIZZU yang berada pada bagian kanan bawah menggunakan font san serif yang terlihat lebih modern. Selain itu bahan dari pallete tersebut bukanlah kaleng seperti Khong Guan tetapi terbuat dari plastik yang memiliki finishing glossy seperti kaleng.

Di bulan November 2019, Mizzu Cosmetics berkolaborsi dengan Khong Guan untuk menciptakan sebuah produk edisi terbatas yaitu "Khong Guan Face Palette". Kolaborasi ini lahir sebagai peringatan ulang tahun ke-7 dari Mizzu Cosmetics. Kolaborasi ini di dahului dengan rangkaian kampanye yang diberi tajuk \#MIZZUCariPapa (https:// mizzucosmetics.com/yuk-ikutan-mizzucaripapa/). Hal ini membuat netizen menjadi penasaran dan menunggu rilisan dari produk tersebut. Menurut Asri Tadda (Tadda, 2015), rangkaian kampanye dan produk kolaborasi dari Mizzu Cosmetics bisa dikategorikan sebagai sebuah strategi promosi yang dilakukan dengan cara kreatif serta memanfaatkan internet marketing.

Akun media sosial Instagram dari Mizzu Cosmetics@ mizzucosmetics saat ini memiliki 169.000 pengikut dan sudah diverifikasi oleh instagram sehingga meningkatkan kepercayaan dari konsumen ataupun calon konsumen. Nilai yang terkandung dalam sebuah desain dari sisi wu- jud biasanya terletak pada aspek emosional komunikasi, dimana emosi tersebut dapat mencipta daya tarik, menghibur, hingga mempengaruhi tindakan seseorang (Pinandita, 2020 : 30). Pada kampanye yang dibuat oleh Mizzu Cosmetics yang bertajuk \#MIZZUCariPapa menggelitik rasa penasaran dari para netizen sehingga merangsang emosi untuk mengetahui lebih lanjut mengenai apa yang akan hadir sebagai produk baru Mizzu Cosmetic sampai akhirnya dapat mempengaruhi keputusan pembelian.

Rangkaian kampanye dimulai oleh sebuah unggahan video pada tanggal 8 Mei 2019 yang memancing rasa penasaran dari netizen pengikut dari akun media sosial@mizzucosmetics.Video tersebut bercerita mengenai seorang ibu yang bertanya mengapa anak-anaknya terlihat sedih. Anak-anak tersebut merasa malu dan sedih karena netizen selalu mempertanyakan keberadaan ayah mereka yang tidak pernah terlihat, sedangkan mereka selalu makan enak. Dengan melihat video tersebut timbul rasa penasaran netizen. Rasa penasaran tersebut merupakan salah satu emosi yang terlibat dalam strategi pemasaran yang melibatkan emotional branding. Terbukti dengan komentar yang diposting netizen dalam unggahan tersebut yaitu dari akun @rika2991 yang berkomentar "Wah wah aku makin penasaran.. \#mizzuxkhongguan" dan @ rachgoddard yang merupakan seorang selebgram juga berkomentar "Gils gils gilsss..Mizzu bikin apa lagi iniihhh?????”.

Rangkaian kampanye itu juga dilanjutkan dengan kompetisi atau yang lazim dikenal dengan istilah giveaway yaitu pemberian hadiah produk Mizzu Cosmetics dan Khong Guan senilai 200 ribu rupiah hingga unit Iphone XS. Pemberian hadiah ini merupakan salah satu strategi untuk meningkatkan jangkauan internet marketing dari produk tersebut. Peserta yang mengikuti giveaway tersebut diwajibkan untuk membuat makeup ala mama Khong Guan serta diharuskan mention dan tag 3 orang teman untuk mengajak mengikuti kompetisi itu. Dalam unggahan tersebut terbukti banyak netizen yang memberikan komentar dan menunjukkan minat mengikuti giveaway tersebut serta mengajak teman-temannya untuk ikut dengan cara mengetag namanya. Hal tersebut merupakan salah satu strategi pemasaran yang memperhatikan aspek menjalin hubungan baik dengan konsum5en. Selain itu kampanye tersebut juga mendapatkan perhatian khusus sehingga dipromosikan dari mulut ke mulut atau meminjam istilah pemasaran yakni word of mouth.

Kampanye \#MIZZUCariPapa tidak hanya melalui unggahan-unggahan dalam post di media sosial instagram @ mizzucosmetics saja. Kampanye juga dilakukan melalui fitur story dalam media sosial instagram @mizzucosmetics. Fitur story adalah fitur untuk berbagi unggahan dalam media sosial instagram yang sifatnya tidak permanen dan akan menghilang dalam kurun waktu 24 jam. Dalam salah satu story yang diunggah pada rangkaian kampanye \#MIZZUCariPapa adalah unggahan dengan visualisasi komik 


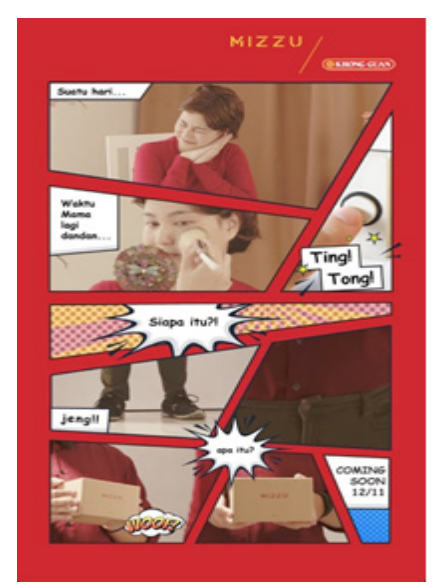

Gambar 7. Kampanye dalam fitur "story" Dari Mizzu Cosmetics

(Sumber: https://www.instagram.com/p/B2GsAawlhO2/)
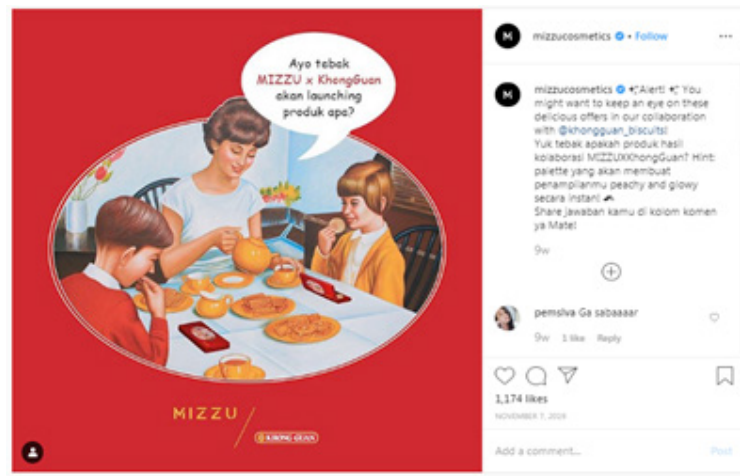

Gambar 8. Kampanye “\#MIZZUCariPapa” Dari Mizzu Cosmetics

(Sumber: https://www.instagram.com/p/B4j2etVFlcn/)

yang bercerita tentang figur mama yang menerima paket kiriman dari mizzu cosmetics. Tetapi isi dari paket tersebut masih belum dibuka dan diakhiri dengan teks "Coming Soon 12/11". Informasi teks tersebut merujuk pada tanggal rilis dari produk "Khong Guan Face Palette". Hal ini selain sebagai pengingat bagi konsumen dari Mizzu Cosmetics juga memelihara rasa penasaran yang dibangun oleh kampanye ini.

Kampanye tersebut dilakukan hingga menjelang peluncuran produk "Khong Guan Face Palette" pada unggahan tanggal 7 November 2019. Unggahan tersebut sudah menampilkan sedikit ilustrasi dari produk, namun belum tampak keseluruhan. Hal ini dilakukan untuk menjaga rasa penasaran dari konsumen yang belum pasti mengetahui rilisan produk tersebut. Disini aspek emotional branding ditingkatkan dengan tambahan visual dari ilustrasi produk yang memancing panca indera dan meningkatkan rasa penasaran. Dalam unggahan tersebut ilustrasi keluarga Khong Guan tidak hanya terlihat menyantap biskuit saja, namun juga dapat terlihat produk kosmetik. Pendekatan imajinatif yang kreatif dalam unggahan ini meningkatkan rasa penasaran terhadap wujud dari produk kolaborasi dan engagement para pengikut dari akun media sosial@miz-

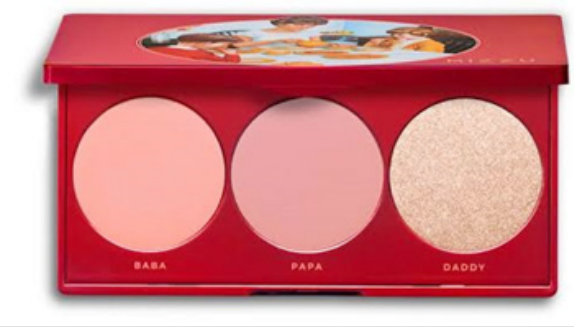

Gambar 9. Nama-nama warna dari Mizzu Cosmetics "Khong Guan Pallete"

(Sumber: https://www.google.com)

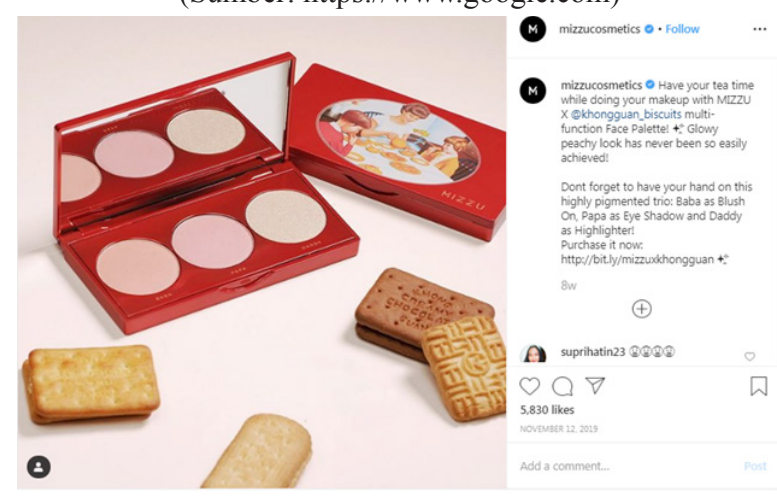

Gambar 10. "Khong Guan Face Palette" Dari Mizzu Cosmetics (Sumber: https://www.instagram.com/p/B4wxQzzlWXb/)

zucosmetics.

Berikutnya pada tanggal 11 November 2019, bertepatan dengan ulang tahun ke-7 dari Mizzu Cosmetics akhirnya dirilis produk kolaborasi antara Mizzu dan Khong Guan. Peluncuran produk secara daring ditandai dengan unggahan mengenai produk tersebut di akun media social@mizzucosmetics pada tanggal 12 November 2019. Varian face pallete dari Mizzu Cosmetics tersebut diberi nama yang unik setiap warnanya sesuai dengan konsep pemasaran dari kampanye \#MIZZUCariPapa yaitu Baba, Papa dan Daddy.

Strategi Pemasaran yang dilakukan oleh Mizzu Cosmetics ini merupakan strategi pemasaran yang kreatif karena melakukan kolaborasi dengan produk lintas fungsi yaitu dengan produk biskuit Khong Guan. Produk Khong Guan sendiri merupakan suatu produk yang sangat memorable bagi sebagian masyarakat Indonesia. Hadirnya Khong Guan si tengah keluarga, terlebih di saat-saat seperti Lebaran membuat masyarakat sangat dekat dan mengenal produk tersebut serta saat melihat memunculkan kenangan jadul dalam perasaan emosionalnya. Strategi pemasaran ini terbukti mampu melibatkan faktor emosional dari kon- 
sumen, memicu rasa penasaran dan meningkatkan hubungan dengan konsumen. Hubungan baik atau engagement dengan konsumen meningkat melalui respon yang didapat pada setiap unggahan dari kampanye tersebut. Strategi pemasaran kolaborasi ini merupakan contoh implementasi emotional branding dalam perancangan aktivitas pemasaran yang dilakukan oleh produsen. Visi dari kedua merek yang ingin menciptakan hubungan yang bertahan lama dengan konsumen ditambah pengalaman pancaindra imajinatif menjadikan kampanye ini berhasil menjadi salah satu inovasi dalam strategi pemasaran melalui internet marketing.

\section{SIMPULAN}

Penelitian ini merupakan sebuah pengkajian yang dibuat untuk melakukan proses analisis pada karya desain komunikasi visual berwujud desain kemasan Mizzu Cosmetics. Proses analisis diawali dengan melakukan tahapan identifikasi atas strategi pemasaran kolaborasi oleh Mizzu Cosmetics bersama biskuit Khong Guan dalam produk "Khong Guan Face Palette". Setelah itu proses analisis melakukan pengkajian dengan metode deskripsi atas desain kemasan Mizzu Cosmetics "Khong Guan Face Palette". Proses analisis dilakukan dengan sistematika metode penelitian deskriptif kualitatif berlandaskan fenomenologis dengan teori utama desain kemasan dan ditunjang oleh teori emotional branding serta teori strategi pemasaran.

Penerapan analisis menggunakan teori desain kemasan dalam desain komunikasi visual dan melibatkan teori emotional branding yang diterapkan pada sebuah strategi pemasaran. Elemen-elemen dalam sebuah desain kemasan menjadi bahan pemaparan dalam metode deskriptif penelitian ini. Desain kemasan umumnya merupakan suatu identitas merek, akan tetapi didalam era kolaborasi hal itu tidak lagi menjadi yang utama. Alternatif yang muncul di era tersebut adalah adanya strategi pemasaran kolaborasi. Strategi pemasaran kolaborasi memungkinkan suatu merek merancang desain kemasan dengan meminjam identitas produk lain yang menambahkan nilai emosionalnya. Strategi pemasaran kolaborasi yang dilakukan oleh Mizzu Cosmetics dan Khong Guan adalah sebuah inovasi yang kreatif dalam menghadapi tantangan pemasaran sebuah produk. Kolaborasi dengan memanfaatkan aspek emotional branding dari sebuah produk yang memiliki citra ikonik di mata konsumen walaupun lintas fungsi memungkinkan sebuah kampanye pemasaran menjangkau audiens yang lebih luas. Dengan merancang desain kemasan yang memiliki nilai ikonik dan emotional dalam benak ingatan audiens terhadap sebuah produk, akan merangsang panca indra untuk memunculkan rasa penasaran dan keterlibatan emosi. Kemasan produk kosmetik "Khong Guan Face Palette" dari Mizzu Cosmetics dirancang sedemikian rupa sehingga memiliki visualisasi kaleng biskuit Khong Guan yang ikonik. Khong Guan sendiri merupakan sebuah produk ikonik yang memunculkan memorable terhadap ke- nangan jadul dalam perasaan emosional.

Emotional branding yang ada pada produk Mizzu Khong Guan Face Pallete di dasari oleh rasa ketertarikan netizen terhadap kampanye \#MIZZUCariPapa yang terlihat dari antusias di tiap postingan instagram@mizzucosmetics. Selain itu setelah mengetahui bahwa kemasan Mizzu Face Pallete tersebut menggunakan visualisasi yang sama dengan kaleng Khong Guan juga membuat rasa tertarik untuk membeli karena merupakan produk terbatas sehingga dapat dijadikan koleksi. Kampanye yang dilakukan dengan tema utama \#MIZZUCariPapa merespons nilai dari produk Khong Guan yang sering dijadikan meme atau parodi dari netizen tentang hilangnya figure seorang ayah. Halhal tersebut juga ditambahkan lagi dengan visi dari kedua merek yang ingin menciptakan hubungan berkelanjutan dengan konsumen, hingga akhirnya kampanye produk kolaborasi "Khong Guan Face Palette" ini berhasil menjadi inovasi dalam strategi pemasaran internet marketing.

\section{DAFTAR RUJUKAN}

\section{Acuan dari buku dengan satu, dua, dan tiga pengarang}

Chandra, G. (2002), Strategi dan Program Pemasaran, Penerbit Andi Offset, Yogyakarta.

Faisal, S. (1992), Format-format Penelitian Sosial, Rajawali Press, Jakarta.

Klimchuk, M.R. (2007). Desain Kemasan : Perencanaan Merek Produk yang Berhasil Mulai dari Konsep Sampai Penjualan, Erlangga : Jakarta.

Kotler, P. (2017), Marketing for Competitiveness, Bentang Pustaka, Yogyakarta.

Pinandita, A. (2020), Rasa-Rasa Emotional Desain Grafis, Penerbit Lakeisha, Klaten.

Norman, D.A. (2004). Emotional Design : Why We Love (or Hate) Everyday Things, Basic Books, New York.

Robert, K.(2004). Lovemark : The Future Beyond Brands, Powerhouse Books, New York.

\section{Acuan dari dokumen online (website/internet)}

Tadda, A. (2015), 5 Strategi Pemasaran Untuk Meningkatkan Penjualan. https://www.eureka.co.id/read/2/5-strategi-pemasaran-untuk-meningkatkan-penjualan.html.

https://www.instagram.com/mizzucosmetics/ https://mizzucosmetics.com/yuk-ikutan-mizzucaripapa/ 